\title{
INFÂNCIA, NORMATIVIDADE E DIREITOS DAS CRIANÇAS: TRANSIÇÕES CONTEMPORÂNEAS*
}

\author{
Rita de Cássia Marchi ${ }^{1}$ \\ Manuel Jacinto Sarmento ${ }^{2}$
}

\begin{abstract}
RESUMO: A globalização de determinado modelo de infância e criança foi estabelecida no século XX por meio de documentos legais de matriz eurocêntrica e hegemonia ideológica e cultural, já identificadas na literatura dos estudos da infância, assinalando a exclusão de crianças que escapam ao enquadramento em que se fundam essas bases: a condição da infância das classes média e superior das sociedades industrializadas. $\mathrm{O}$ debate sobre a normatividade da infância é crucial para impedir que, nos planos teórico e social, crianças sejam excluídas da condição da infância, assim como para compreender como a desconsideração da diversidade de infâncias limita o escopo e a capacidade analítica dos estudos da infância e para compreender mudanças em curso na relação entre adultos e crianças nas dimensóes política, educativa, cultural e internacional.
\end{abstract}

Palavras-chave: Normatividade. Infância. Direitos da criança. Sociologia da infância.

\section{CHILDHOOD, NORMATIVITY AND CHILDREN'S RIGHTS: CONTEMPORARY TRANSITIONS}

ABSTRACT: The globalization of a certain model of child and childhood was established in the $20^{\text {th }}$ century through legal documents with a Eurocentric matrix and ideological and cultural hegemony, which had already been identified in the literature of childhood studies. They pointed out the exclusion of children that do not fit in the framework in which these bases are established: the condition of childhood in the middle and upper classes of industrialized societies. The debate about the normativity of childhood is crucial to prevent children from being excluded from the condition of childhood, both theoretically and socially. Furthermore, to understand how the act of disregard to the diversity of childhood limits the

\footnotetext{
*Este artigo resulta de estágio pós-doutoral realizado no Grupo de Sociologia da Infância do Centro de Investigação em Estudos da Criança, dirigido pelo prof. Dr. Manuel Sarmento, no Instituto da Educação da Universidade do Minho (CIEC/IE-UMINHO), Braga, Portugal. O estágio pós-doutoral teve financiamento da CAPES e da Universidade Regional de Blumenau (FURB, SC, Brasil).

${ }^{1}$ Universidade Regional de Blumenau - Blumenau (SC), Brasil. E-mail: atoseditora@gmail.com

${ }^{2}$ Universidade do Minho - Braga, Portugal. E-mail: sarmento@ie.uminho.pt

DOI: 10.1590/ES0101-73302017175137
} 
scope and analytical capacity of childhood studies, as well as to understand ongoing changes in the relationship between adults and children in the political, educational, cultural, and international dimensions.

Keywords: Normativity. Childhood. Child rights. Sociology of childhood.

\title{
L'ENFANCE, LA NORMATIVITÉ ET LES DROITS DE L'ENFANT: DES TRANSITIONS CONTEMPORAINES
}

\begin{abstract}
RESUME: La mondialisation de certains modèles de l'enfance et de l'enfant a été créée au XXe siècle à travers des documents juridiques de matrice eurocentrique et de l'hégémonie idéologique et culturelle, qui ont déjà été identifiés dans la littérature d'études de l'enfance et qui notent l'exclusion des enfants en dehors du cadre sur lequel se fondent ces bases: la condition de l'enfance des classes moyennes et supérieures des sociétés industrialisées. Le débat sur la normativité de l'enfance est essentiel pour prévenir, de façon théorique et sociale, que les enfants soient exclus de la condition de l'enfance, ainsi que de comprendre comment le mépris de la diversité des enfances limite le champ d'action et la capacité d'analyse des études de l'enfance et de comprendre également les changements en cours dans la relation entre les adultes et les enfants dans les domaines politique, éducatif, culturel et international.
\end{abstract}

Mots-Clés: Normativité. Enfance. Les droits des enfants. Sociologie de l'enfance.

\section{Introdução}

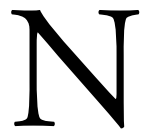

o final dos anos 1970 (menos de 20 anos após publicar a história do surgimento do sentimento de infância na Europa), Philipe Ariés escreveu que "existe o risco de que na sociedade de amanhã [...] a criança não siga concentrando em si, como acontece há um século ou dois, todo o amor e a esperança do mundo" (ARIĖS, 1986, p. 17). O historiador considerou que as sociedades estariam deixando de ser child-oriented como se verificara até os anos 1960 e localizou nos EUA, local onde principalmente se "rendera culto" à criança, o lugar onde mais se evidenciava o surgimento de uma franca hostilidade a seu respeito ou um "refluxo" em relação à importância da infância.

Alguns anos mais tarde, Neil Postman, autor da tese sobre o "fim da infância", também verificou na sociedade americana um crescente sentimento de hostilidade em relação às crianças quando a "ambiência simbólica", que possibilitou o surgimento da infância como valor caro à sociedade, "começou a ser desmontada vagarosa e imperceptivelmente" (POSTMAN, 1999, p. 82).

No final dos anos 1990, Scheper-Hughes e Sargent (1998, p. 28) igualmente corroboraram a previsão feita por P. Ariès, pois para essas autoras "a ideia 
moderna de infância está desaparecendo e as crianças estão perdendo terreno" no quadro de recente proliferação de políticas públicas que lhes são hostis (child-hostile public policies) nos Estados Unidos, Canadá e Reino Unido. E, assim, as ideias de inocência e vulnerabilidade da criança - como centrais no seu estatuto moderno - estão sendo rapidamente substituídas por atitudes hostis nas sociedades contemporâneas ${ }^{1}$. Essas políticas estariam desmantelando rapidamente o welfare state e instaurando, no contexto da nova economia global, uma "sociedade sem deveres" (duty-free society) com a retirada gradual do Estado das questóes do bem-estar de populaçóes vulneráveis, especialmente máes e crianças. Sendo as crianças os mais numerosos e vulneráveis beneficiários dos programas sociais, as mudanças que estão se processando afetam tragicamente as suas vidas: acesso à alimentaçáo, abrigo, educação e cuidados médicos. Para os que acreditam, portanto, na infância como um tempo especial — a ser protegido — no ciclo da vida, a "sociedade sem deveres é a maior tragédia do florescente neoliberalismo do final do século XX".

A afirmação feita por Ariès, nos anos 1970, e evocada por outros investigadores nas décadas seguintes, significa que uma diferente concepção de infância, porventura uma nova forma de construir os modos de relação entre adultos e crianças, estará em curso. Esse prognóstico projeta sobre o processo de "generatividade" (HONIG, 2009) e de construção normativa da infância interrogaçôes e desafios, alguns dos quais são tratados neste artigo.

Assim, o que está em causa neste texto é a "normatividade da infância" que funda o processo de "institucionalização da infância" na primeira modernidade e convenciona os padróes de "normalidade/anormalidade" infantil. Por normatividade, entendemos, portanto, o conjunto de regras e disposiçóes jurídicas e simbólicas (explícitas e implícitas) que regulam a posição das crianças na sociedade e orientam as relaçóes entre elas e os adultos, nos contextos de interaçóes face a face, nas instituiçóes e nas políticas de infância. Neste artigo sinalizamos o processo de construção e de erosão da normatividade da infância, que tem sido hegemônica na contemporaneidade.

\section{Os direitos das crianças e a normatividade da infância}

A construção normativa da infância sofreu diversos desenvolvimentos ao longo dos tempos, mas o século XX foi especialmente importante nessa definição sistemática, por meio de sucessivos documentos legais que, no plano internacional e nacional, regularam a vida das crianças e padronizaram os modos de relação entre o Estado, as famílias e as crianças e, mais latamente, entre estas e os adultos. Esses documentos globalizaram-se e a Convenção Internacional sobre os Direitos das Crianças (CDC), de 1989, instrumento de direitos humanos mais ratificado em escala mundial, tornou-se uma das expressóes mais significativas da globalização política e cultural de um determinado modelo de infância ${ }^{2}$.

Como documento universal sobre os direitos da criança que pretende considerar as múltiplas faces que a infância assume no nível global, a CDC 
é produto de intensas e prolongadas negociações, originadas da complexidade que emerge das diferenças sociais, culturais e religiosas entre as diversas naçóes (FERNANDES, 2009). Essa arena tensa de negociaçóes decorreu não somente do embate político entre Estados com diferentes interesses, desigual acesso a recursos e poder e, em especial, da diversidade de concepçôes de infância e de direitos da criança, mas, também, do contexto político da Guerra Fria, que ampliou a complexidade (e tempo) das negociaçôes (ROSEMBERG \& MARIANO, 2010).

O documento é, todavia, considerado hoje um "ponto de viragem" relativamente às anteriores perspectivas sobre os direitos da criança, devido à sua natureza e conteúdo: o fato de, juridicamente, adotar o formato de convençáo obriga os Estados signatários a aplicarem os seus princípios em leis e na ordem interna dos países, de modo que tenham maior impacto nos cotidianos das crianças e, no que diz respeito ao conteúdo, apresenta-se como símbolo de uma nova percepção sobre a infância e os direitos das crianças. Nessa nova compreensão encontram-se, por exemplo, o direito da criança à tomada de decisão e de voz ativa nos assuntos que lhe dizem respeito (os chamados direitos de participação ou direitos de "liberdade") assim como o reconhecimento, que não havia nas cartas anteriores, de que os direitos das crianças nem sempre coincidem com os de seus pais (FERNANDES, 2009).

A CDC, ao reunir o direito internacional relativo às crianças e jovens, tem sido vista, assim, como o resultado de muita pressão social em torno dos direitos internacionais das crianças e considerada "o mais recente desenvolvimento político destinado a promover e proteger" esses direitos (FRANKLIN, 1995, p. 16). Mas, se esse documento foi particularmente bem recebido pela positividade que atribuiu à infância, com crianças e jovens sendo agora vistos como atores sociais e seres humanos com direitos próprios, e como instrumento vinculativo que leva à defesa desses direitos em nível local, nacional e internacional, assegurando que o interesse superior da criança seja uma preocupação primordial, ele também sofreu, desde cedo, muitas críticas (SGRITTA, 1997; TISDALL \& PUNCH, 2012).

Entre essas críticas está o descompasso na combinação da noção "universal" de direitos com ideias "particulares" sobre crianças e infância, o que cria controvérsias a partir de contextos locais. Também há o fato de que o documento, que prevê os direitos de participaçáo das crianças, paradoxalmente, não as tenha incluído substancialmente em sua elaboração (cf. também ARCE, 2015). Além disso - para alguns críticos - declaraçōes, estatutos ou convenções dos direitos das crianças que não passem por uma análise das relações de dominação, inclusive (e, sobretudo, mas não exclusivamente) as etárias, podem gerar dispositivos que contribuem na ampliação ou reforço do poder adulto sobre as crianças (ROSEMBERG \& MARIANO, 2010; HANSON \& NIEUWENHUYS, 2013).

No geral, os críticos assinalam, entáo, o fato de que a elaboraçáo da CDC foi dominada pelos países do Norte Global (ou "mundo minoritário") ${ }^{3}$, tendo o seu foco nesse mundo e em suas concepçóes de criança e infância. O documento incorporaria, assim, certas ideias sobre infância e criança (por exemplo, a definição por idade 
e o foco exclusivo na percepção delas como indivíduos, olvidando a questão das responsabilidades, interdependências e reciprocidades que envolvem os relacionamentos intergeracionais nas famílias e comunidades) e privilegiaria determinados problemas relacionados às crianças em seus contextos locais, mas não se referiria a outros ${ }^{4}$.

A matriz ocidental cêntrica dessa orientação legal e a hegemonia ideológica e cultural da modernidade dos países do Norte Global já começaram, portanto, a serem identificadas na literatura crítica nos estudos sociais sobre a infância que discutem as tensōes e contradiçóes intrínsecas à CDC sob as perspectivas já assinaladas: sua pretensão universal, mas seu viés ocidental com ênfase nos direitos individuais (de cidadania), e a promulgação simultânea de direitos à proteção e provisão e de direitos de liberdade, expressão e participação na tentativa de conciliar as correntes protecionista e liberacionista vistas por muitos como antagônicas e/ou inconciliáveis (ROSEMBERG \& MARIANO, 2010; HANSON \& NIEUWENHUYS, 2013).

É importante sublinhar que essa orientação normativa sobre a infância não existe apenas na produção legislativa. Um conjunto de assunçóes, formas de conhecimento, ideias, pressuposiçóes e representaçóes sociais incorporam, no seu todo, modos dominantes de resposta às questóes: o que é ser criança? Como agir em face das crianças? São modos dominantes que se exprimem em padróes de comportamento e condutas, hábitos e procedimentos dos adultos em face das crianças e que são igualmente configuradores da normatividade da infância. Se a CDC corresponde, no plano jurídico, a uma concepção de infância que marca determinantemente a perspectiva normativa com fortes efeitos regulatórios da vida das crianças e das açóes e responsabilidades dos adultos diante delas, essa percepção exprime-se também por meio de assunções implícitas, dialogando com a norma escrita de forma nem sempre convergente, mas frequentemente confluente. Assim, em cada momento histórico, o conjunto de orientaçôes normativas, jurídicas e não jurídicas, explícitas e implícitas, constituem o chamado modo de "administração simbólica" da infância. (SARMENTO, 2004). Podemos hipotetizar que, no quadro de uma sociedade globalizada, o mais completo de todos os documentos jurídicos — precisamente a CDC — influi notoriamente no modo dominante de administraçáo simbólica da infância, articulando-se ora de maneira convergente ora divergente com elementos culturais oriundos dos diferentes povos do mundo, na forma como os adultos compreendem e se relacionam com as crianças e como as instituiçôes incluem e se ocupam dos seus membros mais jovens.

Em suma, a influência da CDC não deixa de ser problemática e atravessada atualmente por contradiçôes dificilmente sanáveis.

\section{Os direitos e a norma da infância diante das crianças "das margens"}

A filiação das bases ideológicas e culturais das normas legais e das orientaçóes implícitas que integram a normatividade da infância tende a excluir para as 
margens as crianças que escapam ao enquadramento em que se fundam essas bases, e que é a condição das crianças das classes médias e superiores dos países de capitalismo avançado ou do Norte Global (e das classes médias e altas dos países periféricos). "Fora da norma" ficam milhóes de crianças: a imensa maioria das crianças pobres do Sul Global, as crianças indígenas, as crianças ciganas, as crianças "de rua", muitas enfim, em condições de subalternidade. Como já demonstrado, elas ficam mesmo, em muitas obras da literatura científica sobre crianças, alocadas à condição de "não crianças" (MARCHI, 2007; AITKEN, 2001; COOK, 2009; CONNOLY \& ENNEW, 1996), e isso porque não se enquadram no modelo hegemônico preconizado.

Assim, uma concepção normativa ocidental cêntrica da intervenção política centrada nos direitos tende a exprimir-se sob uma forma que ignora a diversidade de infâncias e a reproduzir a visão da criança "europeia de classe média" da qual parte. Desse modo, tende a ignorar e a excluir formas de vida e de ação infantis que estão "fora da norma", reproduzindo uma visão que não deixa de ser excludente, por mais bem intencionada que seja (MARCHI, 2007; ARCE, 2015).

As crianças que "escapam" à norma da infância, ou a infância que não está adequada à própria norma, são consequência do fato de que a ideia de infância, tal como modernamente construída, não se constitui como realidade possível para as classes econômica e politicamente dominadas. Nesse sentido, a desigualdade de condiçóes de vida e oportunidades entre as diversas crianças, que são normalmente vistas como "imperfeiçôes" ou "deformaçôes" passíveis de serem "corrigidas" com a atribuição de "direitos", são antes características integrantes do processo histórico e social do desenvolvimento do conceito moderno de infâncias . Ou seja, as desiguais condiçóes de viver a infância não são alheias ou externas ao desenvolvimento histórico da sua construção moderna, são antes, sua consequência e, ao mesmo tempo, sua condição (MARCHI, 2007).

$\mathrm{Na}$ verdade, a CDC foi elaborada ao longo de um processo prolongado (desde o chamado Ano Internacional da Criança, em 1979, até a sua aprovação na Assembleia-Geral das Naçóes Unidas, em 20 de novembro de 1989), ao mesmo tempo em que se desenvolvia a resposta neoliberal ao impacto da chamada primeira crise do petróleo, de 1973, resposta esta que, a partir das grandes potências dominantes e da ação regulatória das instituiçóes saídas do chamado consenso de Washington, como o Banco Mundial e o FMI, promoveu uma forma hegemônica de globalização, com desregulação dos mercados, expansão exponencial do capital financeiro e aumento desmesurado das desigualdades sociais e entre as regiôes do mundo. Os efeitos dessa forma de dominação, nos planos social, político, cultural e ambiental, e as suas implicaçóes para a infância, estâo bem documentados (e.g. FASS, 2007; WELLS, 2009; PUNCH, 2016). O elemento paradoxal que a CDC introduz é o da proclamaçáo dos direitos da criança em um momento em que as condiçóes estruturais de sua aplicação, para uma importante parte das crianças de todo o mundo, apareciam fortemente afetadas pelo processo histórico. 
Os direitos que, desse modo, estão enunciados, apenas são garantidos estruturalmente às crianças dos países e das classes sociais que mais ganham com o modelo hegemônico de globalização, mesmo se, de alguma forma ou de outra, todas as crianças do mundo sejam negativamente afetadas por algumas das consequências da desregulação social introduzida pelo capitalismo avançado: degradação ambiental e aumento, por consequência, das doenças originárias da menor qualidade do ar e da água, exposição aos conflitos da "guerra infinita" (COSTA \& LOUÇÁ, 2003), da violência urbana, da degenerescência das relaçóes de sociabilidade, da incerteza em face do emprego e das perspectivas de inserção futura no mercado de trabalho etc. Mas, é certo, são as crianças dos países e dos grupos sociais "perdedores" na nova questáo social introduzida pelo capitalismo globalizado que mais duramente sofrem essas consequências.

Ao hipostasiar a condição social da infância contemporânea, a CDC e as formas dominantes de administração simbólica da infância globalizam uma concepção sobre ela que radica na idealização de determinado meio social e, portanto, de uma ideia não universalizável empiricamente, embora simbolicamente ela alcance alto grau de aceitação ou consenso.

Assim, um determinado tipo de infância, sendo considerado norma, não somente desclassifica todos os outros tipos no plano ideal, mas, mais grave, exclui, no plano empírico - da realidade social cotidiana - determinadas crianças dos direitos que lhes estão internacionalmente assegurados. Certas crianças seriam, assim, "crianças" apenas no plano jurídico. Desse modo, práticas e concepçōes de crianças que se afastam da normatividade definida pelas classes e grupos sociais dominantes podem levar a excluir certas crianças do próprio estatuto social reconhecido da infância: tematizados como "não crianças", os meninos de rua, por exemplo, sofrem dupla exclusão, dos direitos sociais básicos e do valor simbólico inerente ao seu reconhecimento como crianças de jure e de facto (MARCHI, 2007).

O indefensável parece residir no fato da existência de crianças miseráveis, cercadas pelos mais diversos problemas que as sociedades modernas já têm condiçóes de controlar e resolver, ou seja, o fato de a existência de crianças "sem infância" acontecer no interior de um tempo social que não pode oferecer razóes plausíveis para as suas existências. A pobreza, tida como uma abominação e um resquício da pré-modernidade a ser eliminado pelas conquistas da modernidade, não passa agora de um elemento na "infinita variedade" da existência (BAUMAN, 2006). Nesse sentido, as promessas da modernidade não foram somente quebradas, mas também retiradas.

Para Bauman (2006, p. 9-20), a "produção de 'lixo humano"” (seres humanos vistos como "desnecessários" ou "excedentes" - excesso de populaçáo nos países desenvolvidos ou os refugiados de guerra de agora) são o significado mais profundo das conquistas imperialistas e da colonização. Tendo atingido os territórios mais recuados do planeta, a triunfante modernidade náo permite mais que 
se encontrem soluçóes globais para os problemas locais. Contemporaneamente, todos os países (incluídos os com alto nível de desenvolvimento) estão condenados a procurar (em vão) soluçōes locais para problemas cuja causa é global ${ }^{6}$.

Essa análise dos efeitos socialmente negativos do processo de globalização diz respeito, em primeiro lugar, ao fato de que, no plano empírico, as crianças são o grupo geracional mais afetado pelo aumento das desigualdades sociais fomentado pela globalização. A idealização normativa da criança como sujeito de direitos esbarra com o fato de que as que estão "fora da norma da infância" sejam, de alguma maneira, excluídas da promessa da modernidade da infância: essas crianças acabam por ver desconsiderada a sua condição infantil, sendo muitas vezes tematizadas como expressão de uma patologia social, senão mesmo de uma patologia ontológica. Elas, afinal, não têm à sua disposição ou alcance os meios mínimos de se constituírem como "crianças" no sentido moderno do termo (MARCHI, 2007).

Ora, o que os tempos mais recentes parecem trazer à luz do dia, com uma clareza até agora não alcançada, é que essa contradição entre uma idealizada concepção universal da infância assente nos direitos - com crianças protegidas face ao risco e providas das condições de uma vida com dignidade no plano da alimentação, da saúde, da educação, da habitação, do acesso à cultura e ao lazer, e reconhecidas nos seus direitos de participação plena na vida social - e a realidade atual da infância, no plano global, não é mais sustentável. Isto impóe, desde logo, o questionamento teórico da normatividade e a sua diversificação - não será preferível considerar a multiplicidade de concepçôes de infância, abrindo o caminho à aceitação da diversidade dos modos de vida das crianças e das suas relaçôes com adultos, numa perspectiva crítica, cosmopolita e multicultural dos direitos da criança? - , mas também a consideração de novas políticas de infância, mais atentas aos fatores estruturais e que privilegiem as crianças em condiçóes subalternas (considerando os fatores de desigualdade social, cultural, étnico-racial, geográfica, de gênero ou de disability). Fundamental é, porém, que esta contradição não seja resolvida, como parece estar acontecendo, pelo lado da aceitação tácita da supressão ou subalternização dos direitos das crianças em condiçôes especialmente precárias ou vulneráveis.

\section{0 ataque aos direitos das crianças}

Não há, porventura, imagem mais pungente das crianças contemporâneas do que os meninos e meninas em fuga dos seus países em guerra ou em situação de miséria e que morrem afogados nas praias do Mediterrâneo.

A situação do total desabrigo das crianças migrantes faz inapelavelmente recordar as multidóes vítimas do holocausto nazista. De fato, desde há mais de 70 anos a humanidade náo assistia a um êxodo forçado de tal intensidade como o que estamos contemporaneamente vendo. Nesse intervalo de tempo, foi possível 
acompanhar os dramas inenarráveis de multidóes de crianças vítimas de violência, fosse ela a bélica, a urbana, a decorrente das políticas antiambientais ou a social.

O imaginário coletivo está repleto de imagens de crianças vítimas, no seu estado extremo e total, dando forma à barbárie que se imaginou porventura extinta desde Auchwvitz: quando receberam sobre si os bombardeamentos de napalm no Vietnam; as meninas e os meninos esquálidos da fome no Biafra ou na Etiópia; os adolescentes baleados em tantas Columbine; os meninos de rua assassinados na Candelária, no Rio de Janeiro; os pequenos soldados nas lutas que potências ocidentais financiam na busca dos diamantes de sangue; as débeis crianças vítimas das epidemias provocadas pelo HIV em tantos países cuja doença se tornou a primeira causa de morte infantil; as vítimas de Chernobill ou dos tsunamis e outras catástrofes associadas ao aquecimento global e ao descontrole climático originado em um modo de produção que não considera as questóes climáticas e o esgotamento de recursos naturais.

Todas essas situações mostram bem como a segunda metade do século $\mathrm{XX}$ e os primeiros anos deste milênio não deixam nada a dever à violação dos direitos de tempos precedentes. Porém, em todos esses momentos, se manifestou, de forma mais sincera ou mais hipócrita, de modo mais convincente ou mais ineficaz, com maior ou menos consequência, a indignação e até a solidariedade de poderes públicos para com essas crianças vítimas.

Não acontece, contudo, o mesmo com o drama contemporâneo das crianças refugiadas e migrantes. De algum modo elas são a expressão mais direta da denegação dos direitos da criança, precisamente a partir dos países do Norte Global que hegemonizam a sua definição. Com efeito, as crianças que sucumbem afogadas no mar Mediterrâneo fazem-no porque a maioria dos países europeus decidiu fechar as suas fronteiras, em alguns casos (como a Hungria) com barreiras de arame farpado, ao seu refúgio em condiçóes de segurança. O Reino Unido nega o direito de reagrupamento familiar às crianças que o procuram às portas do Mar do Norte, em Calais. Um país como a França expulsa crianças do seu território por não terem a documentação legal exigida pelos acordos de Shengen. Do outro lado do Atlântico, a promessa do presidente recém-eleito nos Estados Unidos, de construção de um muro ao longo da fronteira do país com o México e a reiteração da vontade de expulsão de todos os muçulmanos não documentados arrastam novas ameaças, algumas já concretizadas, sobre as crianças que não integram a maioria wasp (white, anglosaxonic and protestant).

Nunca como hoje tantas crianças tiveram necessidade de procurar refúgio em outro país, por razóes ligadas à guerra ou à pobreza extrema no seu local de origem, nunca como hoje tantas migram sem os seus pais e estáo abandonadas e entregues a si próprias; nunca como hoje elas encontram tantos obstáculos na procura, com as suas famílias (quando ainda as têm), de condições elementares de sobrevivência (cf. UNICEF, 2016). Mas são os poderes públicos do Norte Global que, 
ao mesmo tempo em que proclamam os direitos da criança e invocam a CDC, contribuem poderosamente para essa situaçáo extrema, não apenas em decorrência das suas políticas chauvinistas, discriminatórias e, em alguns casos, abertamente racistas, mas também pelos compromissos bélico-militares assumidos nas guerras que geram o êxodo ou pelos interesses econômicos na exploração dos países pós-coloniais. Essas crianças são a expressão do horror da infância contemporânea. Mas, mais do que uma situaçáo limite, elas exprimem uma condição mais comum: a da violaçáo universal dos direitos da criança sempre que os interesses econômicos ou políticos hegemônicos sobrelevam as necessidades de proteção e desenvolvimento infantil.

Uma significativa expressão disto é patente no modo como a crise econômica e financeira desencadeada em 2008 afetou de modo muito especial as crianças, por meio do aumento da pobreza infantil, da diminuiçáo das políticas sociais direcionadas a elas e suas famílias, da redução do investimento público em educação, saúde e proteção social da infância, no agravamento geral das condiçóes sociais, especialmente devido ao desemprego e ou empobrecimento dos pais, e à redução dos dispositivos de atendimento às crianças em situação de maior vulnerabilidade, às com necessidades especiais e às de minorias éticas. A realidade dos países do sul da Europa, especialmente vulnerabilizados não apenas pela crise, mas por sua gestão pelas autoridades políticas e financeiras da União Europeia, mostra significativa regressão, em alguns casos de décadas, numa parte importante de indicadores sociais de bem-estar infantil (cf. SARASA \& LUPPI, 2012; UNICEF, 2014; SARMENTO et al., 2015).

Em suma, a última década tem evidenciado a profunda contradição entre a normatividade infantil produzida pela modernidade, a partir da sua matriz ocidental cêntrica, e as condiçôes de vida das crianças vítimas das profundas desigualdades geradas na sociedade contemporânea, caraterizada pela globalizaçáo hegemônica do modelo de capitalismo financeiro. Se essa normatividade incorpora uma concepção de bem-estar das crianças, assente em direitos de proteção, provisão e participação, a realidade não apenas contraria aquilo que os documentos jurídicos reguladores preconizam - o que, aliás, sempre aconteceu num quadro de profunda contradição entre a lei escrita e a lei na prática - como, de modo mais grave, o que na presente década parece emergir é um abandono não apenas da retórica jurídica, mas também da consideração das crianças como sujeitos específicos de direitos. As crianças, sobretudo as de grupos sociais mais vulneráveis, diante da crise econômica e da "guerra infinita" passam a ser consideradas, a partir não da sua condição geracional específica, mas como o "outro" das políticas de exclusão, os indigentes, os refugiados, os sem-teto, os apátridas. A crise social atingiu também a norma da infância: Ariès tinha razão.

\section{Conclusão}

O debate acadêmico sobre a normatividade da infância é de grande atualidade no campo dos estudos sociais da infância ${ }^{7}$. E esse debate é crucial, desde logo, 
para impedir que, no plano da teoria e no plano da prática social, as crianças em situação de exclusão fiquem também simbolicamente excluídas da condição da infância por estarem "fora da norma". E também porque, sem compreender a diversidade das condiçóes da infância, ficam profundamente limitados o escopo e a capacidade analítica e interpretativa dos estudos sociais da infância. Sobretudo, o debate sobre a normatividade é essencial para compreender os processos de transição e mudança em curso na relação entre adultos e crianças, nas suas diferentes dimensóes políticas, educativas, culturais e internacionais. Neste texto procuramos argumentar no sentido de considerar que uma concepção hegemônica da normatividade da infância é não apenas excludente da imensa maioria das crianças que náo estáo inseridas nas condiçôes sociais sobre as quais se produziram os princípios referenciais sobre o que é ser criança e como se estabelecem as relaçóes entre adultos e crianças, mas também o fato de que essa concepção parece mesmo estar a soçobrar perante a violência social e institucional que hoje se abate sobre muitas crianças.

Esse é um fenômeno estrutural sobre o qual alguns dos mais importantes historiadores e sociólogos têm se pronunciado. Por exemplo, Beck e BeckGernsheim (2009, p. 33) dão conta da situação de globalização da insegurança e vulnerabilidade das crianças e jovens na sociedade de risco:

[...] the increasing insecurity, wich is becoming the basic experience of the younger generation, is not a local, regional or national phenomenon. Rather, this insecurity is turning into a key experience transcending borders, a commom one.

Por consequência, a análise das transições da normatividade infantil incide essencialmente sobre o que a desigualdade e o risco social implicam nas condiçóes de vida das crianças à escala global, e como diferentes crianças, em condiçóes sociais, geográficas e étnico-raciais distintas, são afetadas por essas desigualdades.

É nesse contexto que a dimensão paradoxal dos direitos da criança, que correspondem a condições sociais das quais está excluída a maioria das crianças do mundo, deverá ser considerada. Como a situação contemporânea das crianças migrantes dramaticamente documenta, a transição da sua normatividade dá-se pelo lado da exclusão e da desconsideração do seu estatuto de sujeito de direitos. A necessidade de se desconstruir analiticamente a produção normativa ocidental cêntrica, a partir dos direitos da criança, não pode significar a sua exclusão do usufruto desses direitos. Pelo contrário, significa que é na análise das desigualdades sociais e nas suas incidências sobre as crianças que se pode sustentar uma orientação política que, despojada da retórica dos direitos das crianças fora das suas condiçôes estruturais de emergência e promoção, enuncie as condiçóes de inclusão, bem-estar e cidadania cosmopolítica de, efetivamente, todas as crianças.

Essa orientação exige a adoção de uma perspectiva crítica que, partindo da análise da diversidade que se encontra nas crianças das "margens", das crianças 
pobres, das crianças institucionalizadas, das crianças que trabalham, das crianças em situação de rua, das crianças subalternas, pode efetivamente compreender e interpretar os processos sociais que conduzem às tensôes e contradiçóes internas na normatividade da infância, às formas plurais de generatividade e às condiçóes efetivas de dominação geracional (SARMENTO \& MARCHI, 2008). É essa perspectiva crítica também a única que pode fundamentar políticas para a infância atentas à diversidade e promotoras de igualdade.

\section{Notas}

1. As ideias de "vulnerabilidade" e "inocência", atribuídas à infância, têm recebido importantes críticas no campo dos novos estudos sociais da infância, e são dirigidas aos aspectos conceituais que enformam modos de subalternização e menorização das crianças. Assim, nessa crítica, não está em causa, de modo nenhum, a necessidade da proteçáo das crianças, especialmente no quadro das novas desigualdades, e sim a consideração de que essa proteçấo não pode subestimar a sua condição como também atores sociais e sujeitos de direitos. Portanto, a crítica acima, de Scheper-Hughes e Sargent (1998), se dirige ao modo perverso como a sociedade atual tem abandonado essas ideias em relação às crianças como, sobretudo, um efeito das políticas públicas neoliberais.

2. Até o momento, todos os países do mundo reconhecidos pela Organização das Naçôes Unidas, salvo os Estados Unidos, ratificaram a CDC, sendo que a maioria das ratificaçóes ocorreu já nos primeiros dez anos após a sua aprovaçáo, o que é inédito em relação a outros tratados internacionais (ROSEMBERG \& MARIANO, 2010).

3. Os termos "mundo minoritário" (Estados Unidos, Europa, Austrália, Nova Zelândia, Japão e Canadá) e "mundo maioritário" (África, Ásia e América Latina) são atualmente usados para designar o que era conhecido como "primeiro" e "terceiro" mundo ou também, mais recentemente, como Norte e Sul Global.

4. Tisdall e Punch (2012) destacam, por exemplo, o fato de a CDC se ocupar do serviço militar infantil que afeta maioritariamente os meninos, mas não fazer referência ao casamento infantil que afeta maioritariamente as meninas, reproduzindo, assim, a visão androcêntrica que constitui o pensamento patriarcal ocidental.

5. Este entendimento que assumidamente tem caráter trágico para o que poderíamos vislumbrar como um "futuro melhor" para a infância no nível mundial é compartilhado por Bühler-Niederberger (2006): “[este] é provavelmente um fato incorrigível e isto tanto mais quanto a individualização mais acentuada demanda estratégias de socialização mais e mais elaboradas, mas que por sua personalização escondem a injustiça”.

6. O autor refere-se aqui aos genocídios ou "limpezas étnicas" promovidos contra povos considerados "primitivos" em nome da expansão de nossa moderna civilização ocidental.

7. Conferir, para esse debate, entre outros, Cook (2009); Honig (2009); Nieuwenhuys (2009); Neyrand e Mekboul (2014); Punch (2016) e Wasshede (2016). 


\section{Referências}

AITKEN, S.C. Global crises of childhood; rights, justice and the unchildlike child. Area, v. 33, n. 2, p. 119-127, 2001.

ARCE, M.C. Hacia un discurso emancipador de los derechos de las niñas y los niños. Lima: IFEJANT, 2015.

ARIÈS, P. La infancia. Revista de Educación, n. 281, p. 5-17, 1986.

BAUMAN, Z. Vies perdues: la modernité et ses exclus. Paris: Payot et Rivages, 2006.

BECK, U.; BECK-GERNSHEIM, E. Global generations and the trap of methodological nationalism for a cosmopolitan turn in the sociology of youth and generation. European Sociological Review, v. 25, n. 1, p. 25-36, 2009.

BÜHLER-NIEDERBERGER, D. Comment étudier les inégalités sociales comme sociologue de l'enfance. In: COLLOQUE INTERNATIONAL REPENSER LA JUSTICE DANS LE DOMAINE DE L'EDUCATION ET DE LA FORMATION, 2006. Lyon, France, maio 2006.

CONNOLY, M.; ENNEW, J. Children out of place. Childhood, v. 3, n. 2, p. 131-145, 1996.

COOK, D.T. When a child is not a child, and other conceptual hazards of childhood studies. Childhood, v. 16, n. 1, p. 5-10, 2009.

COSTA, J.; LOUÇÃ, F. A guerra infinita. Porto: Afrontamento, 2003.

FASS, P.S. Children of a new world: society, culture and globalisation. New York: New York University Press, 2007.

FERNANDES, N. Infância, direitos e participação: representaçôes, práticas e poderes. Porto: Afrontamento, 2009.

FRANKLIN, B. (org.). The new handbook of children's rights: comparative policy and practice. London: Routledge, 1995.

FUNDO DAS NAÇÓES UNIDAS PARA A INFÂNCIA (UNICEF). Children of the recession: the impact of the economic crisis on child well-being in rich countries. Innocenti Report Card 12. Florence: UNICEF, 2014.

. Uprooted: the growing crisis for the refugee and migrant children. New York: UNICEF, 2016.

HANSON, K.; NIEUWENHUYS, O. (orgs.). Reconceptualizing children's rights in international development. Cambridge: Cambridge University Press, 2013.

HONIG, M.-S. How is the child constituted in childhood studies? In: QVORTRUP, J.; CORSARO, W.A.; HONIG, M.-S. (orgs). The palgrave handbook of childhood studies. Houndmills/New York: Palgrave Macmillan, 2009. p. 62-77.

MARCHI, R.C. Os sentidos (paradoxais) da infância nas ciências sociais: um estudo de sociologia da infância crítica sobre a "não criança" no Brasil. 308 f. Tese (Doutorado em Sociologia Política). Programa de Pós-Graduação em Sociologia Política, Universidade Federal de Santa Catarina (UFSC), Florianópolis, 2007. 
NEYRAND, G.; MEKBOUL, S. Corps sexué de l'enfant et norms sociales: la normativité corporelle en société néoliberale.Toulouse: Éditions Érès, 2014.

NIEUWENHUYS, O. Is there an Indian childhood? Childhood, v. 16, n. 2, p. $147-$ 153, 2009.

POSTMAN, N. O desaparecimento da infância. Rio de Janeiro: Graphia, 1999.

PUNCH, S. Cross-world and cross-disciplinary dialogue: a more integrated, global approach to childhood studies. Global Studies of Childhood, v. 6, n. 3, p. 352-364, 2016.

ROSEMBERG, F.; MARIANO, C.L.S. A Convenção Internacional sobre os Direitos das Crianças: debates e tensóes. Cadernos de Pesquisa, v. 40, n. 141, p. 693-728, 2010.

SARASA, S.; LUPPI, F. Crisis Económica y pobreza infantil en algunos países de la Unión Europea. In: NAVARRO, V. (org.). El impacto de la crisis en las familias y en la infancia. Barcelona: Ariel, 2012. p. 17-55.

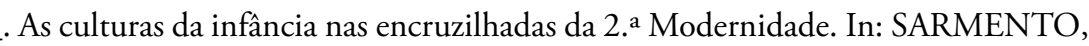
M.J.; CERISARA, A.B. (orgs.). Crianças e miúdos: perspectivas sócio-pedagógicas da infância e educação. Porto: Asa, 2004. p. 9-34.

SARMENTO, M.J.; FERNANDES, N.; TREVISAN, G. A redefinição das condições estruturais da infância e a crise económica em Portugal. In: DIOGO, F. (org.). Pobreza em Portugal: contextos, transformaçóes e estudos. V.N. Famalicão, Húmus, 2015, p. 81-99.

SARMENTO, M.J.; MARCHI, R.C. Radicalização da infância na segunda modernidade: para uma sociologia da infância crítica. Configuraçóes, n. 4, p. 91-113, 2008.

SCHEPER-HUGHES, N.; SARGENT, C. Introduction: the cultural politics of childwood. In: SCHEPER-HUGHES, N.; SARGENT, C. (orgs.). Small wars: the cultural politics of childhood. Califórnia: University of California Press, 1998.

SGRITTA, G.B. Inconsistencies: childhood on economic and political agenda. Childhood, v. 4, n. 4, p. 375-404, 1997.

TISDALL, K.M.; PUNCH, S. Not so "new"? Looking critically at childhood studies. Children's Geographies, v. 10, n. 3, p. 249-264, 2012.

WASSHEDE, C. Normalization of children: Politics and images of children in the Freetown of Christiania. Childhood, v. 23, n. 2, p. 207-220, 2016.

WELLS, K. Childhood in a global perspective. Cambridge: Polity Press, 2009.

Recebido em 31 de janeiro de 2017.

Aceito em 28 de abril de 2017. 